\title{
STABILITY OF HARDLY RESHAPING BERM BREAKWATERS
}

\author{
T. Lykke Andersen ${ }^{1}$, J.W. van der Meer ${ }^{2}$, H.F. Burcharth ${ }^{1}$ and S. Sigurdarson ${ }^{3}$
}

\begin{abstract}
The present paper deals with stability of berm breakwaters designed to be hardly or sometimes partly reshaping. Burcharth $(2008,2011)$ showed by comparison to the performance of a prototype berm breakwater that the Van der Meer formulae for stability of conventional rock armour including low crests could predict the deformations of the front slope in terms of the eroded area. The present paper verifies the method by comparison to model test results. It is found that the Van der Meer formula for plunging waves predicts very well the eroded area of the reshaped profile, even if it is applied in the surging wave area. Moreover, a simple method to estimate the erosion area based on recession formulae and the depth of intersection of reshaped and initial profile is presented and is applicable for hardly reshaping to fully reshaping. Even when using the only very simple and inaccurate estimate of the depth of intersection the last method leads to scatter quite similar to the first method when considering hardly and partly reshaping berm breakwaters. The influence of the slope angle is though expected to be more correctly included for hardly reshaping breakwaters using the method for straight non-overtopped slopes when the slope angle is 1:1.5 or flatter.
\end{abstract}

Keywords: breakwaters ; berm breakwater ; stability ; damage ; recession

\section{INTRODUCTION}

Berm breakwaters are divided into different categories depending on the reshaping and on the construction method. PIANC (2003) gave a classification only on reshaping behaviour. Sigurdarson and Van der Meer (2012) have introduced a new classification of berm breakwaters, which is more precise than the PIANC one. It is partly based on their structural behaviour, such as hardly reshaping, partly reshaping, and fully reshaping. Indicative values are given for the stability number, $H_{\mathrm{s}} / \Delta D_{\mathrm{n}, 50}$, the damage, $S_{\mathrm{d}}$, and the recession, $\operatorname{Rec} / D_{\mathrm{n}, 50}$. The second division is to consider mass armoured berm breakwaters and Icelandic type berm breakwaters. The initial idea of the berm breakwater was to construct the berm with simple construction equipment from one stone class (mass armoured). Due to the construction method a seaward slope angle close to the natural angle of repose (1:1.1 to 1:1.5) was typically used. The profile was allowed to reshape into a more stable S-profile, cf. Fig. 1.

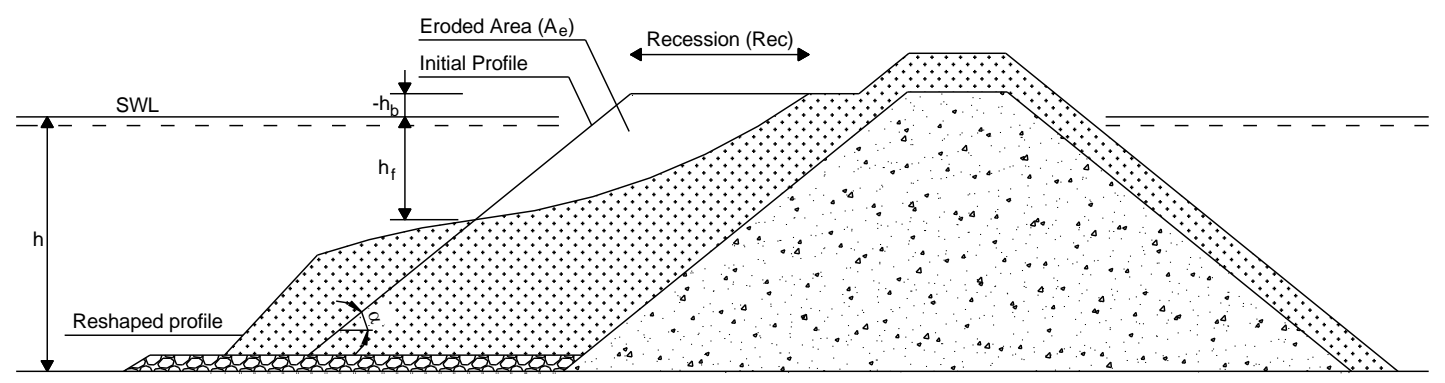

Figure 1. Initial and reshaped profile of a mass armoured reshaping berm breakwater. Note $h_{\mathrm{b}}$ is negative when the berm initially is above SWL.

The profile could be statically stable were stone movements rarely occur when reshaped to the first storms. Alternatively the profile could reshape significantly with stone movements during storms. The fully reshaping berm breakwaters are today designed with stability numbers $H_{\mathrm{s}} / \Delta D_{\mathrm{n}, 50}<3$ as otherwise significant long-shore transport of material in case of oblique waves might occur. Moreover, stone durability might be an issue for these structures.

In Iceland the berm breakwater concept has developed over the years to a design using several stone classes with the large stones placed where they add most to the stability. The large rock in the top part of the berm is in many cases orderly placed to further improve stability. It leads to a very stable but also more complicated cross-section. In the Icelandic berm breakwaters slopes were used of 1:1.25 and $1: 1.3$ up to the middle of the 90 's, but since then the front slope has mainly been 1:1.5. The reason

\footnotetext{
${ }_{1}^{1}$ Aalborg University, Sohngaardsholmsvej 57, DK-9000 Aalborg, Denmark, tla@civil.aau.dk, hfb@civil.aau.dk

2 Van der Meer Consulting BV, P.O. Box 423, 8440 AK Heerenveen, The Netherlands, jm@vandermeerconsulting.nl

${ }^{3}$ IceBreak Consulting Engineers, Smárarimi 46, 112 Reykjavík, Iceland, sigurdur.sig@icebreak.is
} 
being that such a slope was significantly more stable than the very steep slopes. The newly constructed Icelandic berm breakwaters have thus front slopes in the range covered by conventional rock armoured slopes. The Icelandic berm breakwaters are designed as hardly reshaping or partly reshaping structures and in many cases a quite narrow berm has been applied.

The initial damage to berm breakwaters designed as hardly or partly reshaping is in some cases different to what is predicted by the usual applied recession formulae, see. Fig. 2. Moreover, the recession formulae typically have quite large scatter in the area with initiation of damage.

Burcharth $(2008,2012)$ used the Van der Meer and Daemen (1994) formulae for emerged lowcrested structures to assess the reshaping/erosion of the Sirevåg berm breakwater and found excellent agreement with measurements from a storm.

This was the basis for the present study where the static stability formulae are tested on the data of Lykke Andersen and Burcharth (2010) using the hardly and partly reshaping profiles. The front slope used in these tests was $1: 1.25$, i.e. steeper than for conventional structures. The damage calculations will also be compared to predictions using a recession formula to check which method describes best the damage to berm breakwaters in the static stability area.

\section{METHODS OF STABILITY ASSESMENT OF BERM BREAKWATERS}

Different formulae have previously been applied to assess the stability of berm breakwaters. The most common approach has been to describe stability by the berm recession $(R e c)$ which is a key parameter describing the deformation of reshaping structures, cf. Fig. 1.

For dynamically stable structures like rock and shingle beaches an alternative is the formulae of Van der Meer (1992) giving the entire reshaped profile and thus also the eroded area with quite high accuracy for $H_{0}=H_{\mathrm{s}} / \Delta D_{\mathrm{n}, 50}>3-5$.

Stability assessment of hardly and partly reshaping berm breakwaters using methods for conventional rock slopes has been proposed lately. Examples are the formulae for non-overtopped rock slopes and for low-crested structures as applied by Burcharth (2008, 2012).

If the berm is high and/or the front slope less steep the damage might start as local erosion as on a normal straight non-overtopped slope, cf. Fig. 2-A. The initial damage in this case is expected to be in very good agreement with the formulae for static stability of conventional rock slopes as shown by Burcharth (2008, 2012).

A) High berm and gentle front

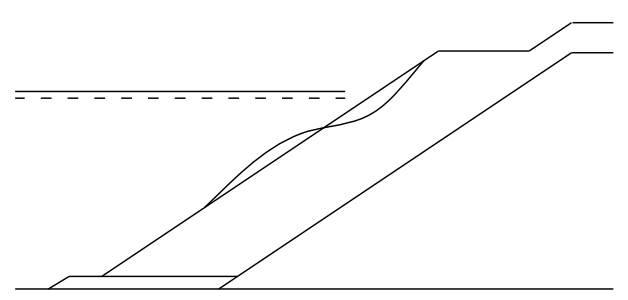

B) Low berm and steep front

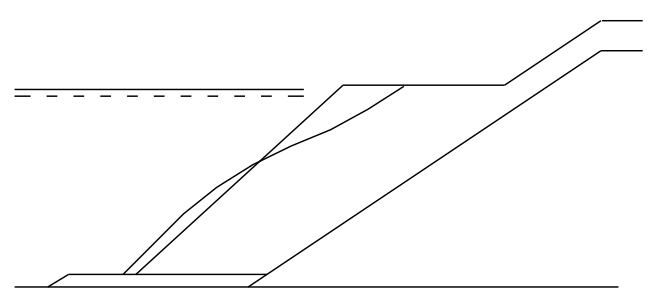

Figure 2. Types of damage progression on berm breakwaters.

If the berm is lower or the slope is steep and quite unstable already to begin with then the damage develops from the berm level and downwards, cf. Fig 2-B. The damage progression in that case is clearly different from that for a non-overtopped straight slope but has more in common with lowcrested structures. The question is if the method of using Van der Meer formulae can be used also to predict the eroded area in cases illustrated in Fig. 2-B. This is investigated in the following. There might be various main issues causing the difference:

1. A large part of the energy passes over the berm causing less damage than on a straight nonovertopped slope. In contrast to low-crested structures a large part of the water though return from the berm and upper slope.

2. The waves feel a flatter slope due to the berm. The berm causes a different breaking type than for a straight non-overtopped slope.

3. The stones on the top of the berm moves more easily due to lack of interlocking from units above.

4. If the berm is low the damage cannot progress as high above SWL as it would on a nonovertopped slope. 
5. The front slope might be very steep, much steeper than for conventional rock structures and this might influence the effect of wave period on the stability of the steep slope.

\section{Existing Recession Formulae}

Many researchers have developed empirical recession formulae to calculate the berm recession, cf. Hall and Kao (1991), Tørum and Krogh (2000), Lykke Andersen and Burcharth (2010) and Sigurdarson and Van der Meer (2011).

In the fitting of the Lykke Andersen formula a very large data set was used covering the entire area from hardly reshaping to reshaping dynamically stable structures, but limited to mass armoured structures only and with a steep slope of 1:1.25. Tørum (2012) tested a number of recession formulae and found that the Lykke Andersen formula was the only one useful for both shallow and deep water conditions. This is expected to be because Lykke Andersen included the influence of the slope angle and water depth based on some considerations on the form of the reshaped profile and mass balance. Below is given the Lykke Andersen recession formula.

$$
\begin{aligned}
& \frac{\operatorname{Rec}}{D_{n, 50}}=f_{h b} \cdot\left[f_{H 0} \cdot \frac{2.2 \cdot h-1.2 \cdot h_{s}}{h-h_{b}} \cdot f_{\beta} \cdot f_{N} \cdot f_{\text {grading }} \cdot f_{\text {skewness }}-\right. \\
& \left.\frac{\left[\cot \left(\alpha_{d}\right)-1.05\right]}{2 \cdot D_{n, 50}} \cdot\left[h-h_{b}\right]\right]
\end{aligned}
$$

Where the influence of the sea state is given by $f_{\mathrm{H} 0}, f_{\beta}, f_{\text {skewness. }}$. For further details regarding the parameters refer to Lykke Andersen and Burcharth (2010). The formula is in Fig. 3 evaluated against the data of Lykke Andersen and Burcharth (2010). The formula was also tested against eleven other data sets which had more scatter and a slightly wider confidence band. For limited reshaping the uncertainty of the Lykke Andersen formula is relatively large corresponding to 2-5 stone diameters. Moreover, for hardly no or only limited recession the recession is not the only parameter relevant. The eroded area $A_{\mathrm{e}}$ as used by Burcharth $(2008,2012)$ is relevant for such structures also because erosion of the front slope will in some cases take place before recession of the berm shoulder occur.
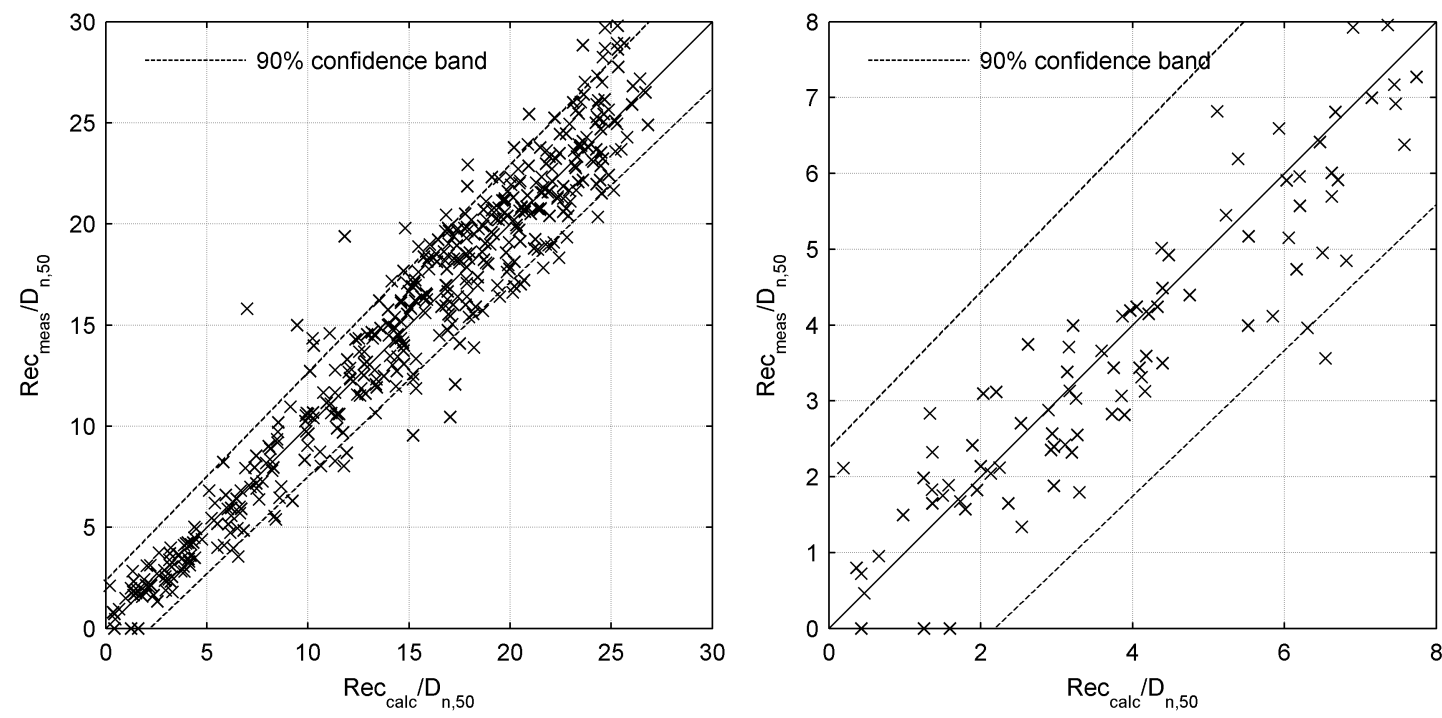

Figure 3. Evaluation of Lykke Andersen and Burcharth (2010) formula against data their own data. Left all data and right focus on smaller recessions. 


\section{Static Stability Formulae of Van der Meer}

The Van der Meer (1988) rock armour formulae for straight non-overtopped slopes is used with $H_{1 / 3}$ substituted with $H_{2 \%} / 1.4$ as non-Rayleigh distributed wave heights were used in many of the tests. The formulae reads:

Plunging waves $\left(\xi_{0 \mathrm{~m}}<\xi_{0 \mathrm{~m}, \mathrm{cr}}\right)$ :

$$
\frac{H_{2 \%}}{\Delta D_{n, 50}}=8.7 P^{0.18} \xi_{0 m}^{-0.5}\left(\frac{S_{d}}{\sqrt{N_{w}}}\right)^{0.2}
$$

and surging waves $\left(\xi_{0 \mathrm{~m}}>\xi_{0 \mathrm{~m}, \mathrm{cr}}\right)$ :

$$
\frac{H_{2 \%}}{\Delta D_{n, 50}}=1.4 P^{-0.13} \cot (\alpha) \xi_{0 m}^{P}\left(\frac{S_{d}}{\sqrt{N_{w}}}\right)^{0.2}
$$

Transition point:

$$
\xi_{0 m, c r}=\left(6.2 P^{0.31} \sqrt{\tan \alpha}\right)^{1 /(P+0.5)}
$$

where $H_{2} \%$ is the incident wave height at the toe exceeded by $2 \%$ of the waves, $\Delta$ is the relative mass density, $D_{\mathrm{n}, 50}$ is the nominal diameter. $P$ is the notational permeability, $\alpha$ the seaward slope angle and $N_{\mathrm{w}}$ the number of waves (use always $N_{\mathrm{w}}<8500$ ). $\xi_{0 \mathrm{~m}}$ is the breaker parameter based on mean wave steepness calculated using the deep water formula and the significant wave height.

The damage parameter $S_{\mathrm{d}}$ is a dimensionless eroded area related to the eroded area $\left(A_{\mathrm{e}}\right)$ by:

$$
S_{d}=\frac{A_{e}}{D_{n, 50}^{2}}
$$

Calculation of cumulative damage after several sea states is in the present analysis following the procedure described by Van der Meer (1985). The procedure is to convert the damage after the previous sea state to an additional number of waves of the current sea state. This additional number of waves is then added to the actual number of waves at the current sea state. This procedure is used because the breakwater in the model tests was not rebuilt after each test but several tests were performed with increasing wave height for constant wave steepness. Because the number of waves in each test is high and wave height always increasing the correction is though not very important in this case as the step in the wave height in most cases is so large that the previous damage is typically converted to a relatively small extra number of waves.

The steepest slope used in the design of the Van der Meer formulae was 1:1.5 and for the homogenous structures the steepest was 1:2. Therefore, the application to steep homogenous slopes as used in many berm breakwaters is not covered by the formulae. Moreover, the formulae are only valid for straight non-overtopped slopes, although correction factors exist for low-crested structures.

Such a correction formula for low-crested emerged structures was proposed by Van der Meer (1988) and later updated by Van der Meer and Daemen (1994). The correction is to replace $D_{\mathrm{n}, 50}$ in the equations for the straight slope with $f_{\mathrm{i}} \cdot D_{\mathrm{n}, 50}$ with $f_{\mathrm{i}}$ given by:

$$
f_{i}=1.25-4.8 \frac{R_{c}}{H_{s}} \sqrt{\frac{s_{0 p}}{2 \pi}} \quad ; \quad f_{i} \geq 1.0
$$

The increase in stability $\left(H_{0}\right)$ for identical damage levels is thus for a crest at SWL set to $25 \%$ independent of the wave steepness using this formulation. For higher relative crest levels the effect become less and decreases fastest for waves with high steepness. For typical wave steepnesses the influence of the low crest can thus be neglected when $R_{\mathrm{c}} / H_{\mathrm{s}}>1.0$. Cumulative damage is dealt with in similar way as given for the non-overtopped straight slopes. 
Most berm breakwaters are designed for no or limited overtopping and therefore negligible transmission. Therefore, above formula is in the present analysis applied to berm breakwaters with the crest freeboard replaced by the berm freeboard, i.e. $R_{\mathrm{c}}=-h_{\mathrm{b}}$ as also done by Burcharth $(2008,2012)$.

This is though not completely correct as the upper slope is then neglected and the correction is expected to be too large as water will return from the upper slope and the berm.

\section{MODEL TEST DATA}

Lykke Andersen and Burcharth (2010) data will be used for the present analysis and includes 695 tests with mass armoured berm breakwaters. The front slope in the tests was 1:1.25 and the berm elevation was always not very high. Therefore, the damage was not just local front slope erosion but progressed to berm recession (Fig. 2-B). The number of waves in each test was 3000 .

For the present study only the data with berm elevation at or above SWL $\left(h_{\mathrm{b}} \leq 0\right)$ is used, i.e. 593 tests. The tests cover everything from hardly reshaping to dynamically stability. The main focus of the present paper is static stability and mainly hardly reshaping berm breakwaters. Therefore, tests with $S_{\mathrm{d}}$ $<20$ are only considered giving 223 tests all with stability number $H_{0}<2.4$.

The damage observations are based on average profiles as measured with a laser profiler before a test series and after each step in the test series. The average profiles are based on app. 100 profiled cross-sections across the width of the model but disregarding the area closest to the side walls. For the tests with the largest armour stones profile measurements was only available after the final wave height and not for each step. Therefore, we only have damage calculations for 52 of the 223 tests. In addition to these 52 tests are two tests with a straight slope of 1:1.25.

\section{APPLICATION OF THE VAN DER MEER ROCK ARMOUR FORMULAE}

The berm was homogenous and core material coarse in the tests. Therefore, $P=0.6$ is applied as notational permeability as for a homogenous structure. The slope in the tests was 1:1.25 which is steep and quite unstable already to begin with and outside the application area of the formulae. Fig. 4 shows the results of the stability formula for non-overtopped slopes for various slope angles for a damage level $S_{\mathrm{d}}=5$.
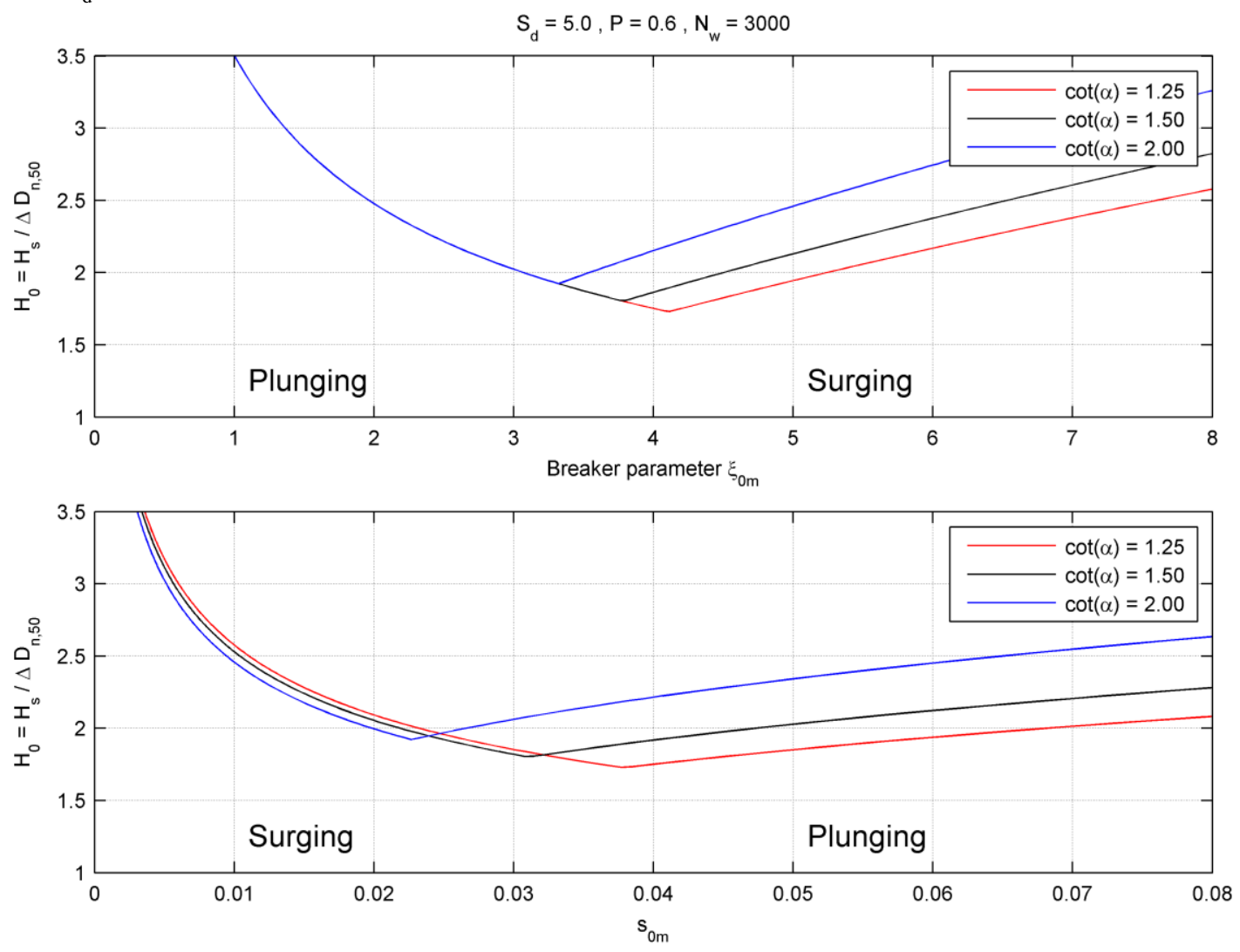

Figure 4. Plot of VdM formulae for straight non-overtopped slopes for damage level $S_{d}=5$. 
The usual plotting method by Van der Meer is to have the breaker parameter on the abscissa axis (upper graph). Another method is to plot it with the wave steepness on the abscisse (lower graph). In the last case it can be seen than for the surging waves the stability is almost independent on the slope angle.

Note that the formula has not been validated for slopes steeper than $1: 1.5$. One alternative is to apply the formulae with slope 1:1.5 and then more damage than predicted should be expected. Alternatively we can extrapolate the formulae to 1:1.25 slopes which for a given wave steepness gives a decrease in the stability in the plunging area while almost no change in the surging area. The amount of stability decrease in the plunging area is an open question which should be validated first for straight slopes. There are two tests with straight slopes that indicate the extrapolation is acceptable (see Fig. 5) and therefore the formulae are applied in the present analyses with slope angle 1:1.25.

Results are given as the cumulative damage and compared with the calculated cumulative damage following the procedure given earlier. The approach for low crested structures is expected to give best results as the damage in the tests always progressed to the berm. Anyway the method for the nonovertopped straight slopes will be tested as well.

The application area of the static stability formula is limited to $S_{\mathrm{d}}<20$, above which the stability might be completely different. Straight 1:1.5 slopes have under layer visible for $S_{\mathrm{d}}=8$ and this limit is thus the limit for conventional structures and given by the red dashed lines in Figs. 5 and 7.
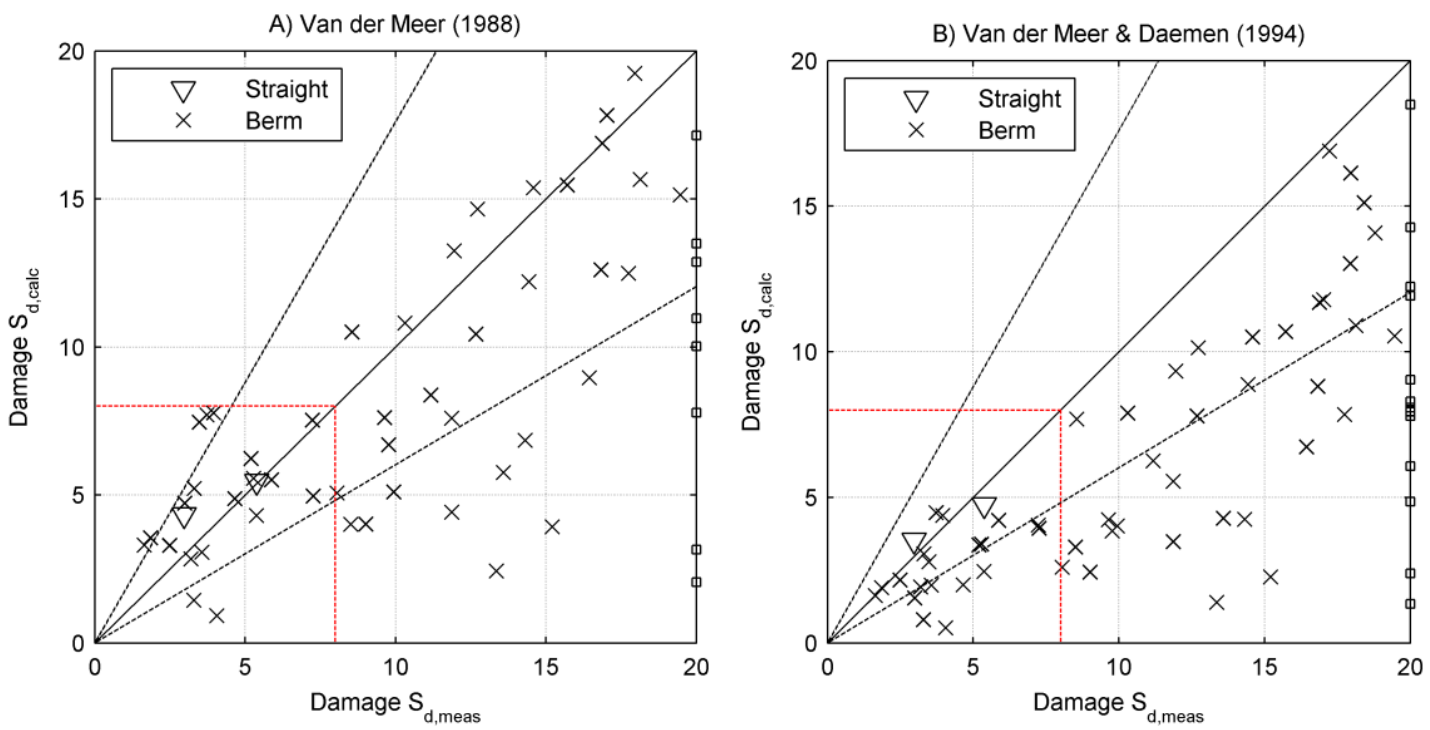

Figure 5. Measured and calculated damage levels using the formulae respectively formula for non-overtopped slopes and for low-crested structures. Dashed black lines show $90 \%$ confidence band according to a coefficient of variation of $6.5 \%$ on the stability index.

The results show that the method without the low-crest correction provides the best results with most data within the $90 \%$ confidence band for the non-overtopped straight slopes. However, there are strong outliers present using both sets of formulae with a huge underprediction of damage. To demonstrate the strong outliers (hardly any damage predicted, very significant damage measured) square points are plotted at $S_{\mathrm{d} \text {,meas }}=20$ if in reality more than $S_{\mathrm{d}}=20$ was measured and more than three times the predicted value. These are therefore strong outliers with in some cases $S_{\mathrm{d}}<5$ predicted and $S_{\mathrm{d}}$ $\approx 50$ measured.

These outliers turn out all to be tests with very low steepness $\left(s_{0 \mathrm{~m}} \leq 0.02\right)$. The formulae predict for such a steepness surging waves and thereby increased stability with decreasing wave steepness. However, the test results show the opposite. There is actually a good explanation for the behaviour observed using the Van der Meer approach on berm breakwaters. As explained earlier there are various differences leading to different response of berm breakwaters compared to straight slopes. The most significant of these effects seems to be that the berm causes a different breaking type than predicted using the seaward slope angle in the breaker parameter. The waves thus feel a flatter slope than the seaward slope and have larger tendency to be plunging for lower steepnesses than for the straight slope. Together with the less stable steep seaward slope this gives more damage for the low steepness waves. 
Another effect is the missing interlocking from stones above which means that stones can roll much easier down from the top of the berm. The effect of the wave steepness on berm breakwaters might therefore be completely different to that of straight slopes.

Based on the first consideration a procedure is tested where the plunging regime is extended to higher Irribaren numbers corresponding to lower wave steepnesses. Fig. 6 shows the Van der Meer (1988) non-overtopped rock slope formulae in non-dimensional way and the 52 data points of interests identified earlier. In the plot the effect of the cumulative damage has not been included as this will require using the formula to calculate an accumulated number of waves. Therefore, most data points should be slightly below the prediction curves which is also the case. From the figure the tendency to a larger area of plunging regime can be clearly identifies. It can be seen that stability always decreases with decreasing wave steepness. This was also found by Lykke Andersen and Burcharth (2010) and the influence of steepness in their formula was reflecting this.

As no transition to the surging regime (increasing stability with decreasing wave steepness) was observed it is for the moment not possible to say if a transition point exists and in that case where it is located. It is therefore not possible to check if the transition point can be determined based on an average slope angle of the structure. However, the decreasing stability with decreasing wave steepness should apply at least to berm breakwaters with a relatively low and wide berm and a steep seaward slope. For other cases the surging waves might occur and thus above correction will be conservative.

Unfortunately the two data points for the straight steep slope are in the plunging regime and thus cannot be used to check if the not existing surging regime is due to the steep slope or due to the berm.
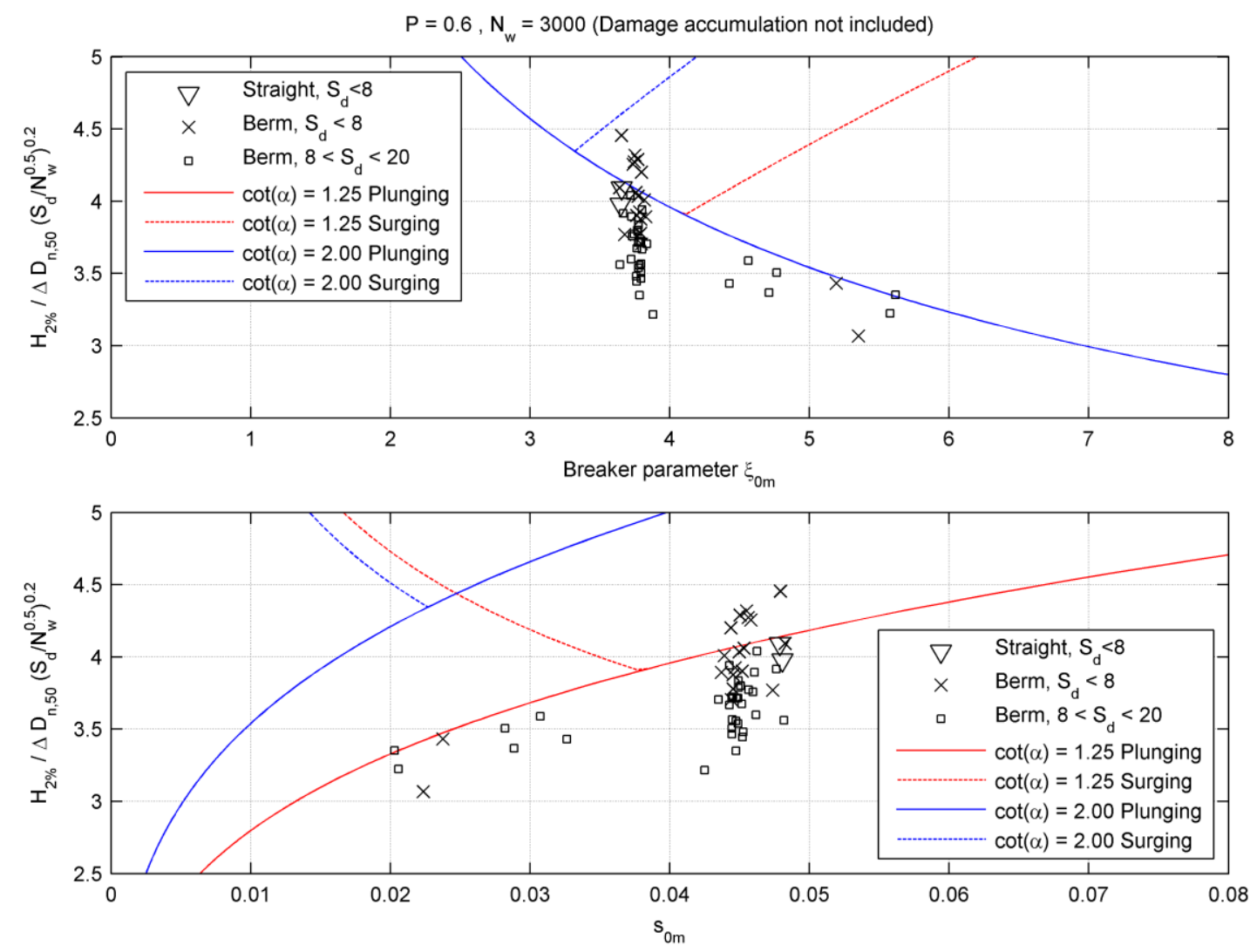

Figure 6. Comparison of Lykke Andersen and Burcharth (2010) data with Van der Meer formulae for straight non-overtopped slopes but excluding the effect of damage accumulation in the test series.

To test the procedure including the effect of the cumulative damage and the low crest correction the data has been plotted in Fig. 7 which clearly demonstrates that the outliers have disappeared and the overall fit is much better when always applying the plunging formulae. It is also worth mentioning that the correction for the low-crested structures (low berm) lead to a significant bias (see Fig. 7-B). It was tested that the same was the case using the formulae based on $H_{\mathrm{s}}$ instead of $H_{2 \%}$. It should though be considered that we apply the formulae for a seaward slope outside the range of validity and this might also be part of the explanation. Another explanation is that the berm does not act as a low crest 
as the energy is not transmitted but a large part of the water returns from the berm and upper slope. The scatter on the data using the method for non-overtopped slopes is not significantly larger than found for conventional rock slopes, cf. Fig. 7-A.
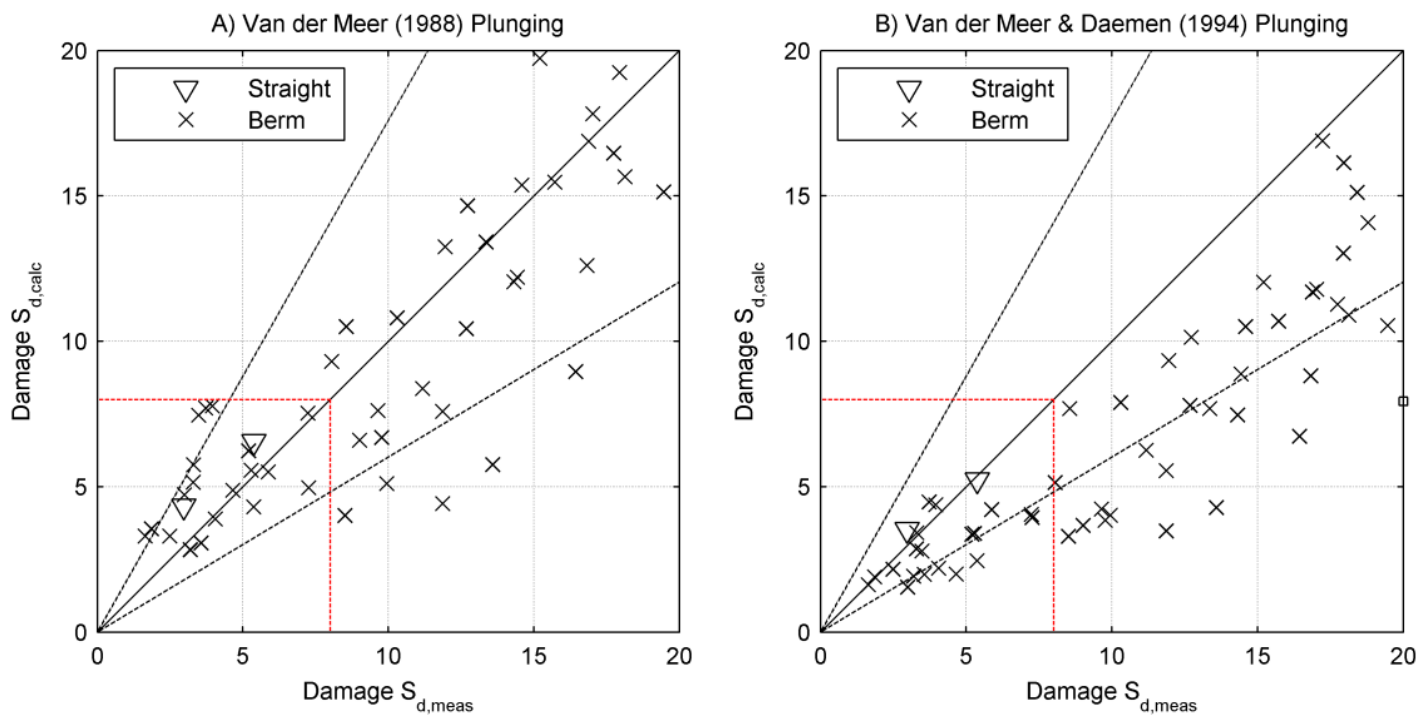

Figure 7. Measured and calculated damage levels using the modified formulae respectively formula for nonovertopped slopes and for low-crested structures (formulae for plunging waves always). Dashed black lines show $90 \%$ confidence band according to a coefficient of variation of $6.5 \%$ on the stability index.

\section{ERODED AREA CALCULATION BASED ON RECESSION AND DEPTH OF INTERSECTION}

Application of stability formulae for rock slopes is limited to damage values not exceeding $S_{\mathrm{d}}=$ 10. This is only for hardly reshaping berm breakwaters. As soon as $S_{\mathrm{d}}$ exceeds values of 10-20 the interesting item is not any longer the damage, but the recession or even the full profile. An interesting part of the erosion is the eroded area, $A_{\mathrm{e}}$. This eroded area for all tested berm breakwaters might be estimated from the recession and the depth of intersection as follows:

$$
A_{e}=0.65 \cdot \operatorname{Rec} \cdot\left(h_{f}-h_{b}\right)
$$

If the profiles are straight lines from the berm recession to the depth of intersection then factor would be 0.5 but is slightly higher due to the curved profile.

Eq. 7 is in Fig. 8 evaluated on the entire Lykke Andersen dataset with berm at or above SWL, using measured Rec and $h_{\mathrm{f}}$.

A) Measured Rec, Measured $h_{f}$

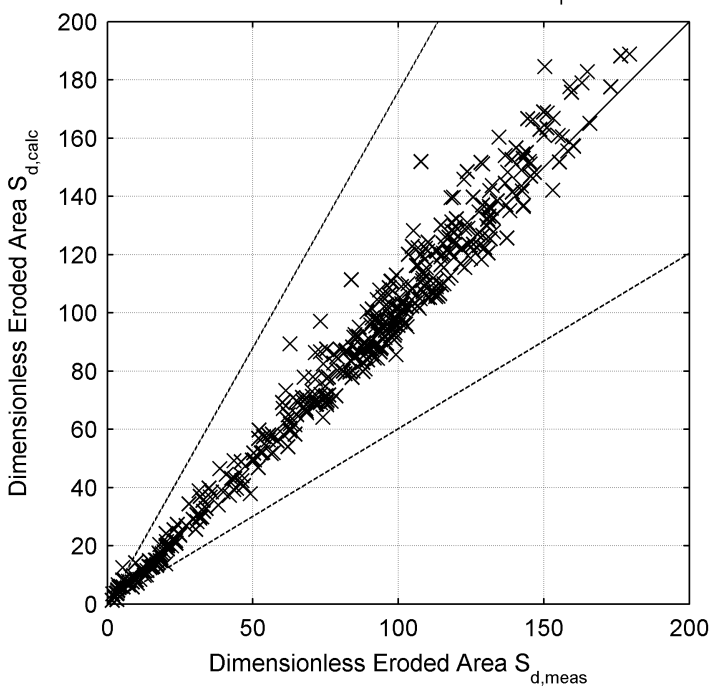

B) Measured Rec, Measured $h_{f}$

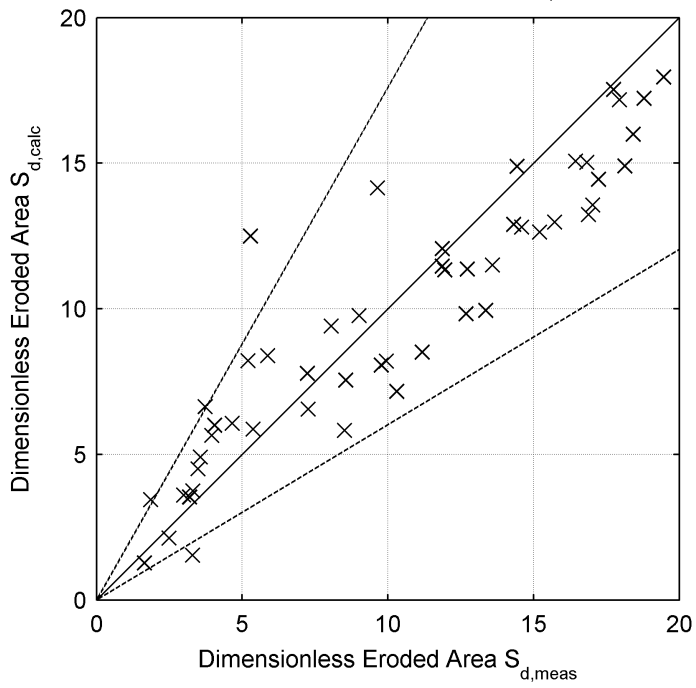

Figure 8. Evaluation of Eq. 7 using measured values of recession and depth of intersection. Dashed lines are repetition of the $90 \%$ confidence band from Fig. 7 . 
The approach looks very promising thereby supporting Eq. 7. In the graphs not the eroded area, $A_{\mathrm{e}}$, is given, but the dimensionless eroded area $S_{\mathrm{d}}$. For static stability $\left(S_{\mathrm{d}}<10\right)$ this is called damage, but for real reshaping it should be called dimensionless eroded area.

The recession formula of Lykke Andersen and Burcharth (2010) is then applied in combination with the actual measured $h_{\mathrm{f}}$. The results are given in Fig. 9 showing the influence of the scatter on the recession formula.
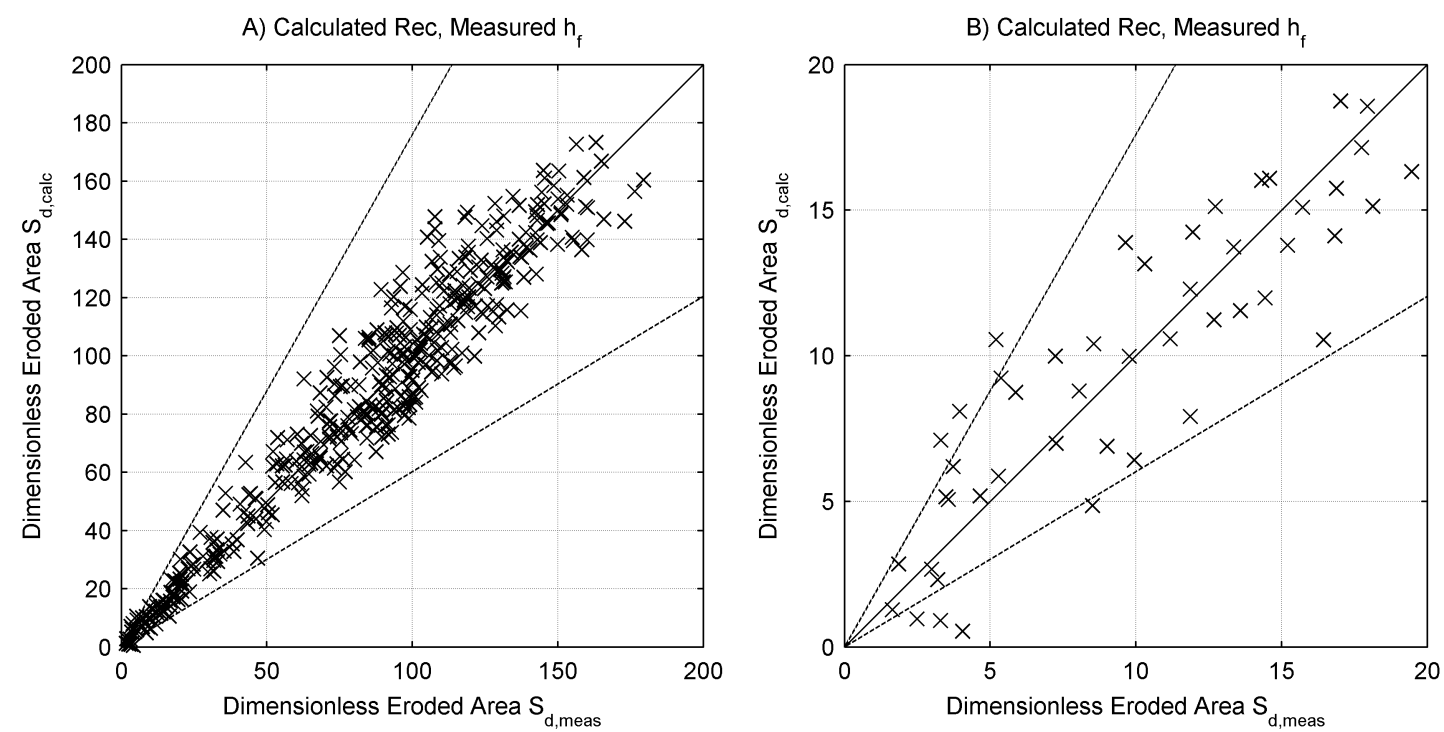

Figure 9. Evaluation of Eq. 7 using Lykke Andersen and Burcharth (2010) formula for recession and measured values of depth of intersection. Dashed lines are repetition of the $90 \%$ confidence band from Fig. 7 .

As a last step the only existing empirical formula for the depth of intersection is introduced of Tørum and Sigurdarson (2003):

$$
h_{f}=0.2 h+0.5 D_{n, 50} \quad \text { for } \quad 12.5<h / D_{n, 50}<25
$$

Fig. 10 shows an evaluation of that formula against the present data. It can be seen that the formula of Tørum underestimates $h_{\mathrm{f}}$ for most of the present tests. The behaviour of $h_{\mathrm{f}}$ is however expected to be much more complicated than expressed in Eq. 8. For the 1:1.25 slope a simple correction to remove the strong bias is to replace the coefficient 0.2 by 0.3 in Tørums formula, i.e.

$$
h_{f}=0.3 h+0.5 D_{n, 50} \text { for } \cot (\alpha)=1.25
$$

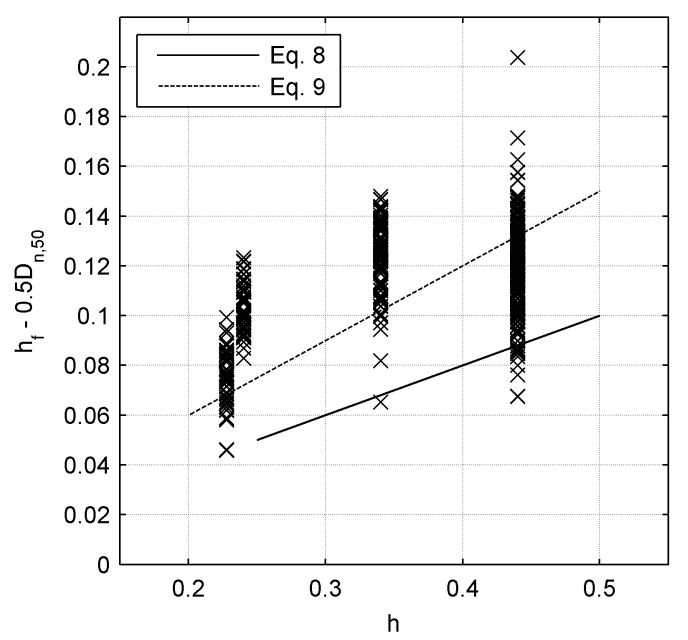

Figure 10. Evaluation of Eqs. 8 and 9 using Lykke Andersen and Burcharth (2010) data.

Even with this simple formula for $h_{\mathrm{f}}$ the scatter is of the same order of magnitude as by using the Van der Meer formula (compare Figs. 7-A and 11-B). The method is valid for both hardly reshaping 
and reshaping berm breakwaters, cf. Fig. 11-A. Scatter might be reduced further by fitting a better formula for $h_{\mathrm{f}}$ than of the very simple type suggested by Tørum. The influence of the slope angle is though expected to be more correctly included by application of the Van der Meer formula when considering initiation of damage.
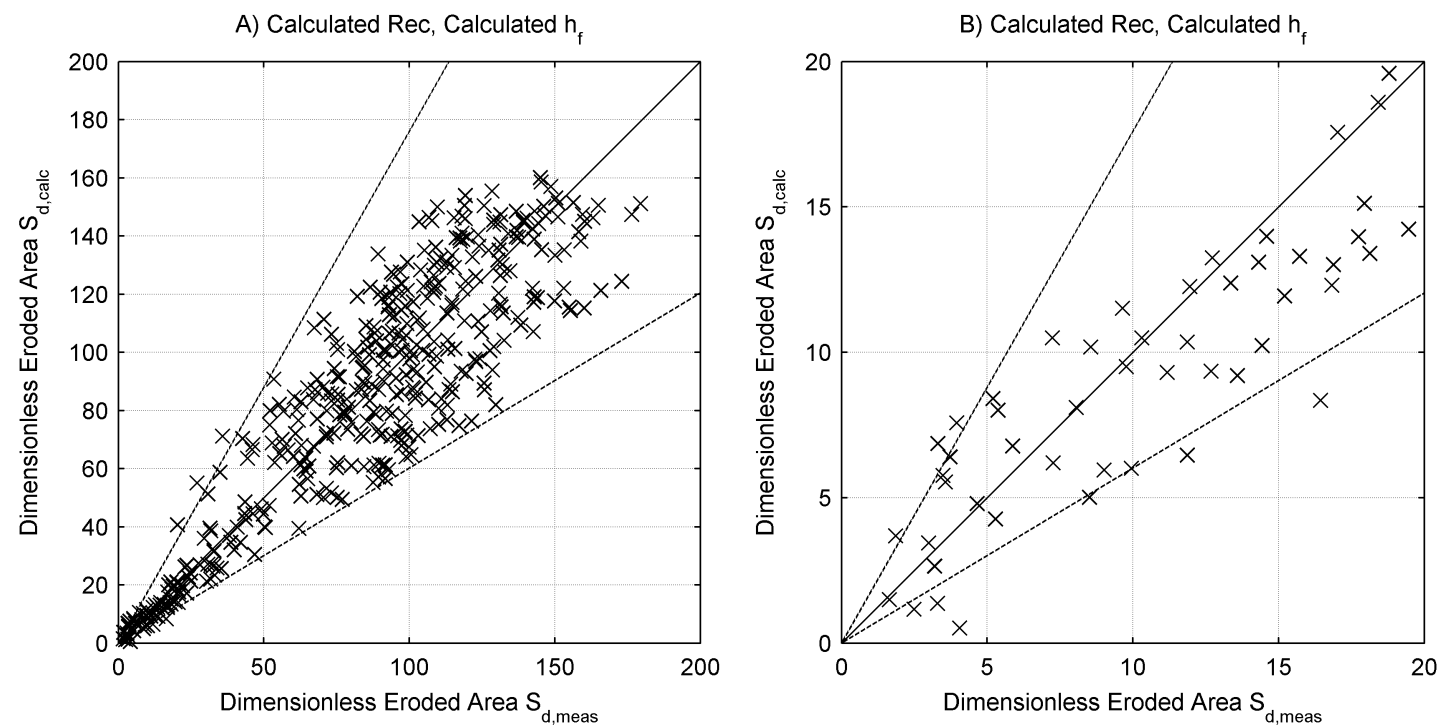

Figure 11. Evaluation of Eq. 7 using Lykke Andersen and Burcharth (2010) formula for recession and Eq. 9 for depth of intersection. Dashed lines are repetition of the $90 \%$ confidence band from Fig. 7.

\section{CONCLUSIONS}

The present paper has identified reasons for differences in stability for berm breakwaters and nonovertopped straight rock slopes. The most important difference seems to be that the berm changes the type of wave breaking on the structure.

Two methods for stability evaluation of hardly and partly reshaping berm breakwaters have been proposed and evaluated against Lykke Andersen model test data. The first method is the application of the Van der Meer formulae for non-overtopped rock slopes, but corrected for the wave breaking type with plunging breakers also for very low wave steepness. When applying the plunging formula the scatter was not significantly larger than for conventional rock slopes.

The second method is to use a recession formula. If the eroded area is wanted this can be estimated based on the recession and the depth of intersection. Even with a very simple empirical formula for the depth of intersection the second method leads to similar amount of scatter as the first approach. Initiation of damage is though expected to be better predicted with the Van der Meer formula.

\section{REFERENCES}

Burcharth, H.F. 2008. Aspects of breakwater design. Presentation at COAST 2008, Trondheim, Norway.

Burcharth, H.F. 2012. On front slope stability of berm breakwaters, Coastal Engineering, submitted.

Hall,K. and S. Kao. 1992. A study of the stability of dynamically stable breakwaters. Canadian Journal of Civil Engineering, Vol 18, pp. 916-925.

Lykke Andersen, T. 2006. Hydraulic Response of Rubble Mound Breakwaters. Scale Effects - Berm Breakwaters. PhD Thesis, Series Paper No. 27, Dept. of Civil Eng., Aalborg University.

Lykke Andersen, T. and H.F. Burcharth. 2010. A new formula for front slope recession of berm breakwaters, Coastal Engineering, Vol. 57, pp. 359-374.

PIANC (2003). PIANC MarCom Report of Working Group No. 40. State-of-the-Art of Designing and Constructing Berm Breakwaters. International navigation Association. PIANC General Secretariat, Brussels, Belgium.

Sigurdarson, S. and J.W. van der Meer. 2011. Front slope stability of the icelandic-type berm breakwater. . ASCE, Proc. Coastal Structures 2011, Yokohama, Japan. 
Sigurdarson, S. and J.W. van der Meer. 2012. Wave overtopping at berm breakwaters in line with EurOtop. Proc. 33rd Int. Conf. on Coastal Eng., Santander, Spain.

Tørum, A. and S.R. Krogh. 2000. Berm breakwaters. Stone quality. SINTEF Report No. STF22 A00207. Civil and Environmental Engineering, SINTEF.

Tørum, A., and S. Sigurdarson. 2003. PIANC Working Group No. 40: Guidelines for the Design and Construction of Berm Breakwaters. Breakwaters, Coastal Structures and Coastlines, pp. 373-384.

Tørum, A., M.N. Moghim, K. Westeng, N. Hidayati and Ø. Arntsen. 2012. On berm breakwaters: Recession, crown wall wave forces, reliability. Coastal Engineering, Vol. 60, pp. 299-318.

Van der Meer, J.W. 1985. Stability of rubble mound revetments and breakwaters under random wave attack.

Van der Meer, J.W. 1987. Stability of Breakwater Armour Layers - Design Formulae, Coastal engineering, Vol. 11, pp. 219-239.

Van der Meer, J.W. 1988. Rock slopes and gravel beaches under wave attack, Delft Hydraulics Communication No. 396.

Van der Meer, J.W. 1992. Stability and wave transmission at low-crested rubble-mound structures, Journal of Waterway, Port, Coastal and Ocean Engineering, Vol. 120.

Van der Meer, J.W. and I.F.R. Daemen. 1994. Stability of seaward slope of berm breakwaters. Coastal Engineering, Vol. 16, pp. 205-234. 